\title{
Baby, It's Cold Outside - or how hot is hot, how cold is cold?
}

\author{
Edwin C. Constable*
}

\begin{abstract}
Frank Loesser's song epitomises our fixation with temperature. But how do we define how hot is hot and how cold is cold? This short article looks at the history of temperature and why life today is much simpler than it was in the past.
\end{abstract}

Keywords: History of Science $\cdot$ Temperature $\cdot$ Thermometers

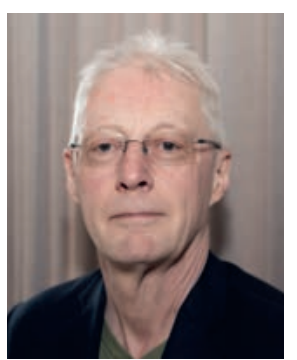

Edwin (Ed) Constable is professor of chemistry at the University of Basel. He studied chemistry at the University of Oxford before migrating to "the other place", holding fellowships and a lectureship at the University of Cambridge. He moved to Basel in 1993. His interests in chemistry are broad-ranging with a particular emphasis on the role of metals in modifying the properties of materials. He was one of the founders of metallosupramolecular chemistry and his current interests centre on the development of a sustainable materials chemistry. He has long been interested in the history of science, believing that in order to understand today's world, we also need to understand from where we have come.

\section{Introduction}

"It's a nice warm day" or "It's a bit cooler than yesterday" how often do we hear remarks like this in normal conversation? In our everyday life, we quantify the warmth or the chill using the Celsius (or centigrade) scale, sometimes remembering that our American friends use something strange with numbers like 32 and 212 being important! In our scientific lives, we use the absolute scale, where the temperature in kelvin is simply that in Celsius plus 273.15 . From where did these numbers come? Are they really absolute? And what do they have to do with melting butter or freezing oil of aniseed? The measurement of temperature was not always as simple as it is today and to understand the temperature units of today, we need to look to history.

\subsection{Before Temperature!}

Humans have probably always had a subjective sense of temperature - "It's hot", "I'm cold". What we forget today is that the quantification of temperature is a modern phenomenon dating back only half a millennium. Before the beginning of the 17 th Century CE, the closest to a quantitative temperature scale was adverbial - "It's very hot", "I'm not so cold today". This is not to say that early history is not a part of our story.

\section{Before the Thermometer was the Thermoscope}

\subsection{The Thermoscope}

A thermoscope is a device that shows changes in temperature, typically a tube in which a liquid rises and falls with temperature changes. It differs from a thermometer in that there is no scale and the device cannot be used to measure a specific temperature. So a thermoscope is a temperature sensor without a scale - it tells you about changes in temperature in a non-quantitative manner. The first documented thermoscope appears to be in Pneumatica

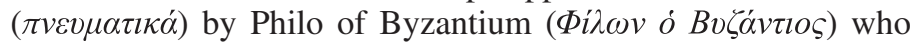
described a system in which one end of an inverted U-tube was sealed into a hollow lead sphere and the other end immersed in an open container of water. When the lead sphere was cooled, water rose up into the U-tube, and when the sphere was heated, the water was driven back into the container. Hero (or Heron) of Alexandria who lived in the first Century CE described a similar device in his own work entitled Pneumatica. The rediscovery by European thinkers in the late medieval period of the philosophical and scientific work of the early Greek, Roman and Arabic civilizations reignited interest in these devices. By the early-to-mid $16^{\text {th }}$ Century CE, many leading scientists had become interested in thermoscopes. There has been healthy debate regarding which of these scientists should be viewed as 'the father of the thermometer'. Claims with more or less validity have been made for Santorio Santorio, Galileo Galilei, Cornelius Drebbel and Robert Fludd. We will not enter into this debate, but the interested reader is referred to publications by Fabrizio Bigotti ${ }^{[1]}$ and others. ${ }^{[2,3]}$

\subsection{What is a Thermometer?}

Before the widespread availability of digital devices, the majority of thermometers were based upon the expansion of a liquid in a glass envelope with a reservoir (bulb) placed in the region where the temperature is to be measured and a long graduated capillary (Fig. 1). To remove a dependency on atmospheric pressure, the bulb and capillary are usually sealed. The liquid must have a higher thermal expansion than glass and upon increasing the temperature, the expansion of the liquid results in it rising up the capillary. Most thermometers are graduated linearly, which makes the assumption that the thermal expansion of the glass can be neglected and that the coefficient of expansion of the liquid is constant over the temperature range of interest. This latter assumption is more-or-less true for most liquids unless they are close to a phase change.

\section{Temperature Scales, from the Sublime to the Ridiculous}

\subsection{Water, Water, Everywhere}

Our choice of a linear scale implies that we have (at least) two fixed points. And so our journey begins. Santorio Santorio 


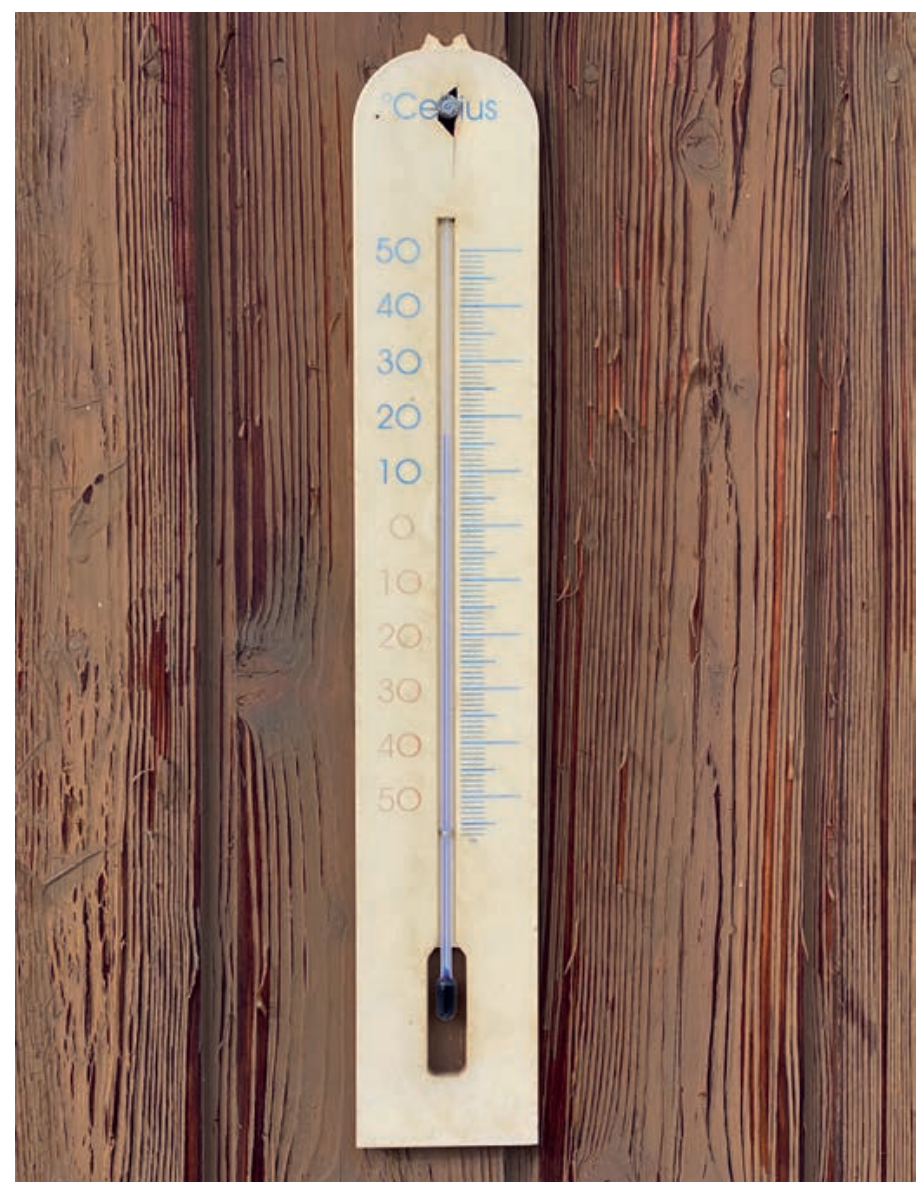

Fig. 1. A liquid-in-glass thermometer of the type familiar before the advent of the digital thermometer.

(Fig. 2) used a glass globe connected to a glass tube immersed in coloured water and marked the water level in the tube when the globe was cooled in snow and when it was at room temperature. Room temperature is both subjective and variable, but this system set the concept for all early temperature scales. As those of us who live in the northern hemisphere are frequently reminded, water is one of the commonest molecules on Earth and it is no surprise that many of the earliest temperature scales were linked to properties of water, typically the melting point of ice and the boiling point of water. Santorio subsequently suggested the heat of a candle flame as the high point in his scale, although this is a subjective and variable measure.

Over the course of the $17^{\text {th }}$ Century CE, proposals for the temperature low point included: the coldest winter day, the first night frost, the temperature of deep caves, congealing aniseed oil, freezing water or melting ice. Similarly, the fixed temperature high point included suggestions to use: the warmest summer day, boiling water, boiling ethanol, melting butter and body heat. Of these, the only ones which can be seen to have any basis in a physical constant are those relating to the freezing and boiling points of liquids.

Edmond Halley the astronomer recommended the boiling point of ethanol as a fixed point, but this requires either an ethanol-water azeotrope of known composition or 'pure' alcohol. His fixed low point was not so convenient - he proposed the temperature of one of the cellars at the Paris Observatory, which had a constant temperature year-round.

Although the freezing point of water is a relatively good fixed point, the boiling point is not quite as fixed as we would like because it depends upon the pressure and, thus, upon the altitude at which the measurement is made. Furthermore, the absolute values of the boiling and melting points of water and ice depend on the

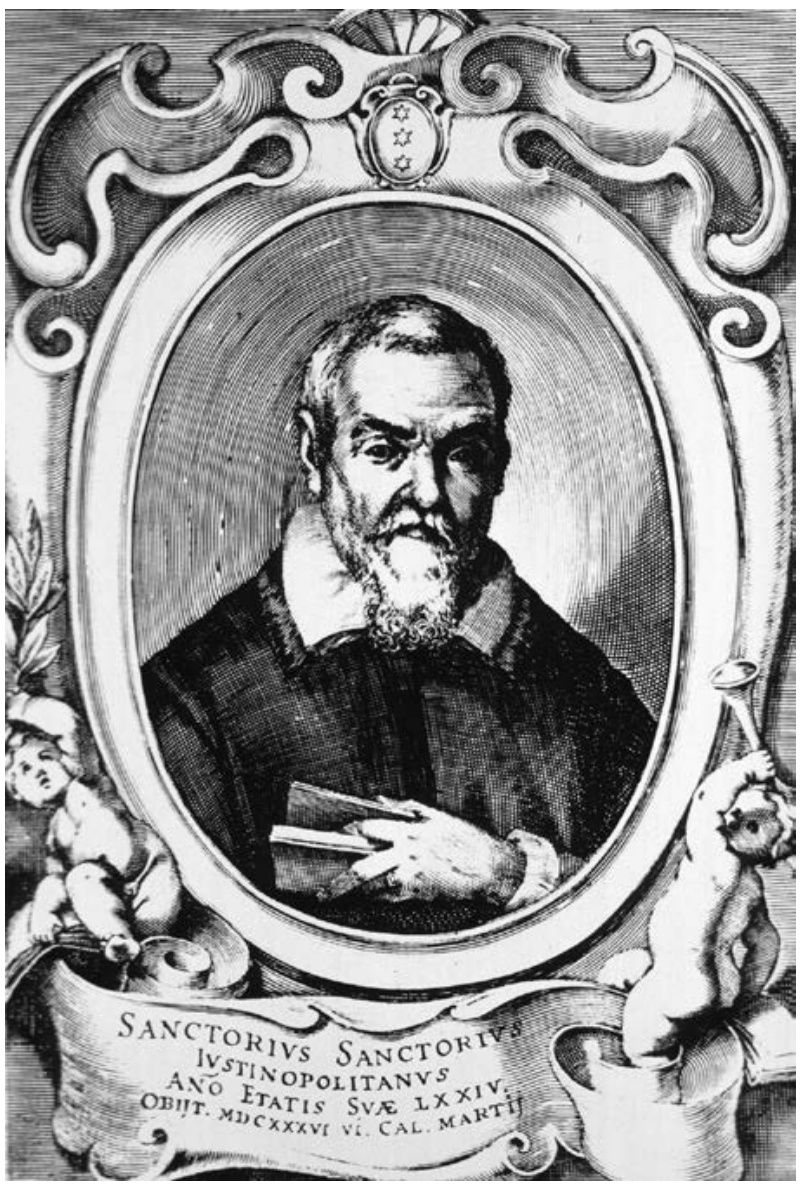

Fig. 2. Santorio Santorio (1561-1636) arguably the inventor of the modern thermometer (Giacomo Piccini, Public domain, via Wikimedia Commons: https://commons.wikimedia.org/wiki/File:Sanctorius.jpg).

purity of the water, with dissolved substances lowering the freezing point and raising the boiling point. Even if fixed points could be agreed upon, there remained the problem of assigning numerical values to them. Today, it is 'obvious' that a higher temperature should have a higher value associated with it, however this was not always the case, as we shall see.

\subsection{Assigning Numbers and Direction}

Moving from the relative 'close to the freezing point of water' or 'near the boiling point of water' to a quantitative description of temperature requires assigning numerical values to the fixed points and a (preferably) linear scale between and beyond them. ${ }^{[4,5]}$ One of the earliest attempts to do this dates to 1701 when Oled Christensen Rømer fixed the freezing point of brine (sea-water) to $0^{\circ}$ and the boiling point of water to $60^{\circ} .{ }^{[6 a, b]} \mathrm{He}$ subsequently revised this to remove the uncertainty in the concentration of sea-water but retained his original scale, defining the freezing point of water as $7.5^{\circ}$. It is now time for one of the greatest scientists of the era to enter the stage - Isaac Newton. His zero point was the temperature at which water began to freeze and he had a number of other physically meaningful reference points including the boiling point of water ( 33 or $34^{\circ}$ ), the melting points of the

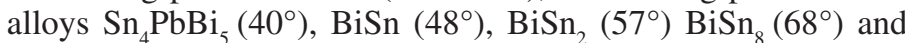
the melting points of bismuth $\left(81^{\circ}\right)$ and lead $\left(96^{\circ}\right)$. This spans the range $273.15-600.61 \mathrm{~K} .{ }^{[7]}$ However Newton also included more subjective 'fixed points', such as 'the greatest heat of a bath which one can endure for some time when the hand is dipped in and is kept still' and 'the heat at midday about the month of July'.

The time had come for Daniel Gabriel Fahrenheit (Fig. 3a) to define his scale. He initially defined a number of fixed points - the lowest temperature reached by a water-ice-ammonium chloride freezing mix $\left(0^{\circ} \mathrm{F}\right)$, the freezing point of water and the temper- 
ature of the human body $\left(96^{\circ} \mathrm{F}\right)$. The Fahrenheit scale was subsequently refined to fix the freezing and boiling points of pure water as $32{ }^{\circ} \mathrm{F}$ and $212^{\circ} \mathrm{F}$ respectively. ${ }^{[8]}$ In the same way that the modern Celsius scale is converted to kelvin by adding 273.15, the 'scientific version' of Fahrenheit is denoted the Rankine scale and defined as Fahrenheit plus 459.67.

At the same time as Fahrenheit was defining his scale, the French scientist René Antoine Ferchault de Réaumur was proposing an alternative one in which the freezing and boiling points of water were defined as $0^{\circ}$ and $80^{\circ}$ respectively. The liquid used in the thermometer was important in determining its characteristics and Réaumur used alcohol, which expanded $8 \%$ between the two fixed points (hence the choice of a span of $80^{\circ}$ ). This scale was still to be encountered until recently in niche activities such as cheese-making and the manufacture of confectionary. Fellow Frenchman Joseph Nicolas de l'Isle used mercury as the liquid in his thermometer and defined the boiling point of water as $0^{\circ}$. However, he defined his scale in terms of the contraction of the mercury column on cooling, with the consequence that larger values were associated with lower temperatures in modern language. Specifically, he defined his degree as a reduction of the volume of mercury by $1 / 100000$; thus, if the boiling point of water was $0^{\circ}$, the lowest temperature he recorded (a Moscow winter) was $2500^{\circ}$. It took Josias Weitbrecht to redefine the scale to more manageable units with the boiling and freezing points of water as fixed points at defined at $0^{\circ}$ and $150^{\circ}$ respectively.

Anders Celsius (Fig. 3b) received an example of de l'Isle's thermometer and adopted the boiling and freezing points of water as his fixed points, defining these as $0^{\circ}$ and $100^{\circ}$ respectively. ${ }^{[9]}$ The inversion to the familiar modern Celsius scale with boiling and freezing points of water defined as $100{ }^{\circ} \mathrm{C}$ and $0^{\circ} \mathrm{C}$ was due to Carl Linnaeus (subsequently Carl von Linné) better known for the introduction of the binomial nomenclature system for naming organisms that is used to this day. The influence of Linnaeus on chemistry is often forgotten, but the modern system of binary chemical notation (sodium chloride, potassium nitrate etc.) introduced in France shortly before the revolution, was inspired by his work on the nomenclature of organisms. And so we arrive at the modern day!

\section{So what is this temperature thing, anyway?}

\subsection{The Modern Temperature Scale (2019)}

The Système International d'Unités (SI) is responsible for defining the nature and value of the fundamental constants and units used in science. Historically, the SI based all definitions upon seven base units (the metre, the kilogram, the second, the ampere, the kelvin, the mole and the candela). These units remain, but in 2018 the SI decided to define all units in terms of physical constants. ${ }^{[10]}$ In other words, the former base units are no longer fundamental, but are defined by seven 'true' physical constants. Those physical constants are the caesium hyperfine frequency, the speed of light in vacuum, the Planck constant, the elementary charge, the Boltzmann constant, the Avogadro constant and the luminous efficacy of a defined visible radiation.

It is useful to consider the kelvin to understand consequences of these changes (and provide an insight into the reasons why they were necessary). The unit of thermodynamic temperature is the kelvin, $\mathrm{K}$, which was originally defined in terms of the triple point of pure water at which ice, water and water vapour are in thermal equilibrium. This was assigned the temperature $273.16 \mathrm{~K}$. This definition, however, was not so simple to realize as hoped: it required pure water (almost impossible to obtain) of well-defined isotopic composition, and in 2018 the SI moved away from the physical measurement of a bulk property of a chemical substance. The kelvin is now defined by

$1 \mathrm{~K}=2.2666653 \frac{\Delta v_{\mathrm{Cs}} h}{k}$
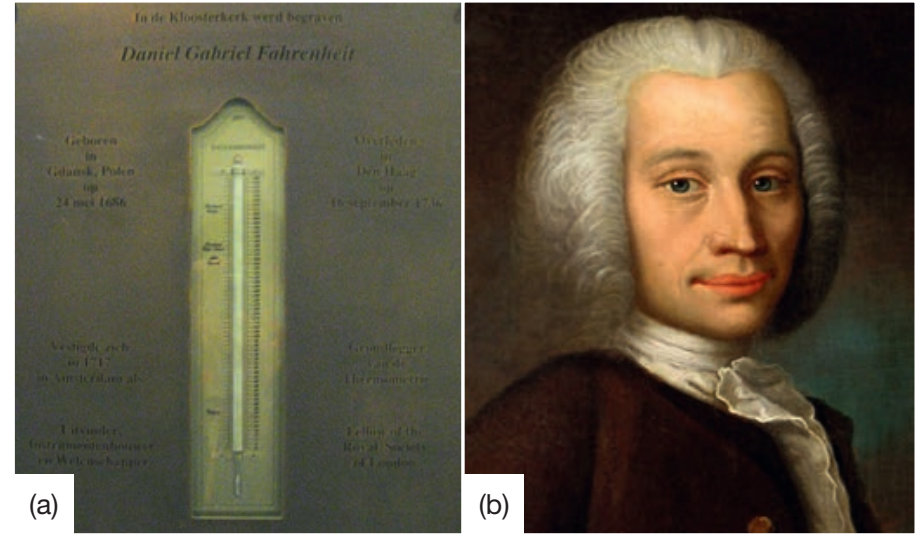

Fig. 3. (a) Daniel Gabriel Fahrenheit's (1686-1736) grave immortalizes his contributions to science (Donarreiskoffer, CC BY-SA 3.0, via Wikimedia Commons: https://commons.wikimedia.org/wiki/File:Daniel_Gabriel_ Fahrenheit,_place_of_burial.jpg) and (b) Anders Celsius (1701-1744) gave us the scale that is most commonly used today (Olof Arenius, Public domain, via Wikimedia Commons: https://upload.wikimedia.org/ wikipedia/commons/8/81/Headshot_of_Anders_Celsius.jpg).

in which $k$ is the Boltzmann constant $\left(1.380649 \times 10^{-23} \mathrm{~J} \mathrm{~K}^{-1}\right), h$ is the Planck constant $\left(6.62607015 \times 10^{-34} \mathrm{~J} \mathrm{~s}\right)$ and $\Delta v_{\mathrm{CS}}$ is the hyperfine transition frequency of caesium (9 $192631770 \mathrm{~Hz}$ ). Precise, but a long way from Newton's 'the heat at midday about the month of July'.

\subsection{What is Temperature?}

The definition of the kelvin given in Eqn. (1) is scientifically precise and accurate but far removed from our subjective perceptions of heat and cold. In this final section, we address the meaning of a word that we have used without qualification throughout this short article - temperature. Temperature is ultimately a measure of the thermal energy present in a substance. Increasing the amount of thermal energy raises the temperature, whereas decreasing the amount of thermal energy lowers the temperature. As discussed above, temperature is measured by a thermometer which was traditionally calibrated to physical properties of substances but is now (at least in principle) calibrated according to the definition of the kelvin in Eqn. (1).

Thermal energy is manifested in heat, which is the flow of energy from one body to another. At $0 \mathrm{~K}$, a body contains no thermal energy (no more heat can be extracted). The concept of an absolute zero $(0 \mathrm{~K})$ is first found in the ideal gas law, Eqn. (2):

$$
p V=n R T
$$

where $p$ is the pressure of a gas $\left(\mathrm{Pa}\right.$ or $\left.\mathrm{kg} \mathrm{m}^{-1} \mathrm{~s}^{-2}\right), V$ is the volume of a gas $\left(\mathrm{m}^{3}\right), T$ is the temperature $(\mathrm{K})$ and $R$ is the gas constant (8.314 $462618 \mathrm{~J} \mathrm{~mol}^{-1} \mathrm{~K}^{-1}$ or $\mathrm{kg} \mathrm{m}^{2} \mathrm{~mol}^{-1} \mathrm{~K}^{-1} \mathrm{~s}^{-2}$ ) and $n$ is the number of moles of gas (mol). This law implies a temperature at which the pressure or volume tend to zero - the absolute zero (Fig. 4). Heat flow and thermal energy are regulated by the four laws of thermodynamics which may be simply formulated:

Zeroth law: If two systems are each in thermal equilibrium with a third system, then they are also in thermal equilibrium with each other;

First law: The total energy of an isolated system is constant and, although energy can be transformed from one form to another, it can be neither created nor destroyed;

Second law: Heat does not spontaneously pass from a colder to a hotter body;

Third law: The entropy of a system approaches a constant value as its temperature approaches $0 \mathrm{~K}$. 


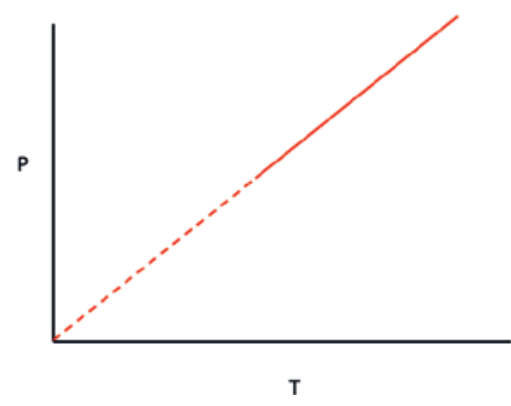

Fig. 4. The ideal gas law in operation. A given volume of gas is cooled and the pressure measured. The ideal gas law indicates that the plot of $P$ versus $T$ should be linear. The intercept on the $T$ axis is the absolute zero of temperature. In reality, this experiment is not possible, because (i) the majority of gases do not exhibit ideal gas behaviour and (ii) all gases condense to the liquid or solid phase at some temperature. These phenomena are indicated on the diagram by the solid red line which represents the temperature region in which ideal behaviour is exhibited and the dotted line, which is the extrapolation to the intercept with the T axis.

All of these highly technical laws and definitions are actually useful in helping us arrive at a subjective, as well as an objective, understanding of temperature. Imagine standing barefoot in a room with one foot on a wooden flooring tile and the other on a stone flooring tile. The room is in thermal equilibrium and the wooden and the stone tiles are at the same temperature (zeroth law). Nevertheless, the stone feels colder than the wood. Heat will flow such that the third system (you) comes into thermal equilibrium with the wooden and the stone tiles (zeroth law). Assuming that your temperature (typically $310 \mathrm{~K}$ ) is higher than the wooden and stone tiles, heat will flow from you to the floor, rather than vice versa (second law).

Two additional properties of the materials now define our subjective concept of temperature - the heat capacity and the thermal conductivity. The heat capacity of a material is the amount of heat needed to produce a unit change in temperature of a given mass of a material, whereas the thermal conductivity of a material is a measure of its ability to conduct heat. There will be a greater heat flow from you to a material that has a higher thermal conductivity or a lower heat capacity. The thermal conductivity of wood is very much lower than stone and its heat capacity is higher. Both of these mean that more heat will flow from you to the stone than to the wood. You lose less heat to the wood than to the stone and so the wood will feel 'warmer' than the stone, even though both are at the same temperature.

\section{Concluding Remarks}

This short article has traced the development of the temperatures scales that underlie so much of our modern understanding of science and of our daily life. I hope that this journey has proved informative and has made you think a little about things that are normally taken for granted.

Received: November 8, 2020

[1] a) F. Bigotti, J. Early Mod. Stud. 2018, 7, 73; b) F. Bigotti, J. Healthc Commun. 2016, 1,1

[2] M. K. Barnett, Osiris 1956, 12, 269.

[3] H. C. Bolton, 'Evolution of the thermometer 1592-1743', The Chemical Publishing Co., 1900.

[4] J. Shectman, 'Groundbreaking Scientific Experiments, Inventions and Discoveries of the 18th Century', Greenwood Press, 2003.

[5] H. Chang, 'Inventing Temperature: Measurement and Scientific Progress', Oxford University Press, 2004.

[6] a) K. Meyer, Nature 1937, 139, 585; b) J. N. Friend, Nature 1937, 139, 586

[7] U. Grigull, Wärme- und Stoffuibertragung. 1984, 18, 195.

[8] J. N. Friend, Nature 1937, 139, 395.

[9] A. Celsius, K. Sven. Vetenskapsakad. Handl. 1742, 3,171.

[10] 'The International System of Units (SI)', Bureau International des Poids et Mesures, 2019.

\section{License and Terms}

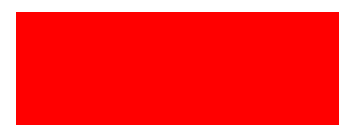

This is an Open Access article under the terms of the Creative Commons Attribution License CC BY 4.0. The material may not be used for commercial purposes.

The license is subject to the CHIMIA terms and conditions: (http:// chimia.ch/component/sppagebuilder/?view=page \&id=12).

The definitive version of this article is the electronic one that can be found at https://doi.org/10.2533/chimia.2021.50 